\title{
A FORMAÇÃO DO CURRÍCULO UNIVERSITÁRIO: ESTUDO DE CASO SOBRE O PROJETO PEDAGÓGICO DO CURSO DE BACHARELADO EM TURISMO
}

\author{
MENEZES, Paula Dutra Leão de* \\ TEIXEIRA, Célia Regina*
}

\begin{abstract}
RESUMO
O ensino superior em turismo surgiu em decorrência do desenvolvimento do setor no contexto da sociedade capitalista, em um período que ocorre a ampliação do ensino, destinado a atender ao mercado de trabalho. No Brasil, a criação e expansão do ensino superior em turismo ocorreram num momento em que havia forte influência das teorias tecnicistas advindas do modelo norte-americano. Nesse contexto, este artigo analisa a formação do currículo universitário em curso de Bacharelado em Turismo considerando a influência da política educacional para os cursos de graduação no país. Trata-se de um estudo de caso realizado em uma universidade federal localizada na região nordeste. Ao final, são abordados os elementos teórico-curriculares com seus pressupostos, verificando a influência da teoria pós-crítica na construção dos currículos e a adoção de uma racionalidade técnica. Especialmente, observou-se que há uma clara definição do perfil profissional, com competências e habilidades desejáveis para o egresso que deve permitir o atendimento a uma racionalidade do mercado. Por fim, evidencia-se que a construção do currículo prioriza as diretrizes da política educacional do país.
\end{abstract}

Palavras-chave: Currículo universitário. Bacharelado em Turismo. Política educacional.

\footnotetext{
*Doutoranda em Humanidades Y Artes (Educação), Universidad Nacional de Rosario (Argentina). Professora da Universidade Federal da Paraíba (UFPB); Centro de Comunicação Turismo e Artes (CCTA); Departamento de Turismo e Hotelaria (DTH).

** Professora Orientadora. Doutora em Educação: Currículo, PUCSP. Professora da Universidade Federal da Paraíba (UFPB); Centro de Ciências Aplicadas e Educação (CCAE); Departamento de Educação (DED).
} 


\title{
e-Curriculum
}

\section{TRAINING COLLEGE CURRICULUM: CASE STUDY ON THE PEDAGOGICAL PROJECT OF THE BACHELOR OF TOURISM COURSE}

\author{
MENEZES, Paula Dutra Leão de
}

TEIXEIRA, Célia Regina*

\begin{abstract}
Higher education in tourism emerged as a result of the development of the sector in the context of capitalist society, in a period that extends the teaching, intended to serve the labor market. In Brazil, the creation and expansion of higher education in tourism occurred at a time when there was strong influence of the technicist theories coming from the North American. In this context, this article analyzes the formation of the undergraduate curriculum in tourism considering the influence of the educational policy for the undergraduate courses in the country, it is a case study carried out in a federal university located in the northeast region. At the end, the theoretical curricular elements are approached with their assumptions, verifying the influence of post-critical theory in the construction of curricula and the adoption of a technical rationality. Especially, it was observed that there is a clear definition of the professional profile, with skills and abilities desirable for the egress that should allow the attendance to a rationality of the market. Finally, it is evident that the construction of the curriculum prioritizes the guidelines of the educational policy of the country.
\end{abstract}

Keywords: University curriculum. Bachelor of Tourism. Educational policy.

\footnotetext{
*PhD student in Humanities and Arts (Education), National University of Rosario (Argentina). Professor at the Federal University of Paraíba (UFPB); Communication, Tourism and Arts Center (CCTA); Department of Tourism and Hospitality (DTH).

** Guiding Teacher. PhD in Education: Curriculum, PUCSP. Professor at the Federal University of Paraíba (UFPB); Center for Applied Sciences and Education (CCAE); Department of Education (DED).
} 


\section{INTRODUÇÃO}

A partir da segunda metade do século XX, a atividade turística se expandiu juntamente com o capitalismo e, em consonância o setor turístico, passou a ser também economicamente parte importante em vários países. Foi nesse contexto que a educação em turismo ganhou visibilidade, com a criação dos primeiros cursos na área de turismo, datada do início do século XX, em países como França, Alemanha, Áustria e Estados Unidos (REJOWSKI, 1996).

Para Rodrigues e Menezes (2010), no Brasil, o primeiro curso de turismo foi fundado na década de 1970, em meio à conjuntura de ditadura militar de modelo desenvolvimentista, voltada para a economia de mercado. Barreto, Tamanini e Silva (2004) complementam que a universidade brasileira nesse momento sofre influências tanto do humanismo francês, quanto do pragmatismo imprimido pelo modelo norte-americano de ensino tecnicista.

A partir de 1995, inicia-se uma nova política nacional de educação no Brasil, que é consubstanciada em 1996, com a Lei de Diretrizes e Bases Nacionais (LDB) e, depois, em 2004, com o Sistema Nacional de Avaliação da Educação Superior (SINAES) - espaço de debates e também normatizador, em que as discussões sobre os currículos dos cursos de graduação vêm sendo redimensionados e impulsionados.

No caso dos cursos de turismo, até meados dos anos 2000 evidencia-se um aumento significativo, notadamente nas Instituições de Ensino Superior (IES) privadas. Contudo, após esse período registra-se o fechamento dos cursos nas IES de ensino privado. De acordo com o com o Censo da Educação Superior - MEC/INEP (2005; 2014): em 2005, existiam 476 cursos de Bacharelado em Turismo, sendo 437 em IES privadas e 39 em IES públicas; e em 2014, o número total caiu para 222 cursos de Bacharelado em Turismo, sendo 166 em IES privadas e 56 em IES públicas.

Nesse cenário, surgem algumas reflexões sobre o currículo do curso de Bacharelado em Turismo - currículo esse que se reflete na formação recebida pelo egresso e pode estar em sintonia com o fechamento dos referidos cursos no país. Assim, este estudo de caso analisa a formação do currículo universitário em um curso de Bacharelado em Turismo oferecido por uma universidade federal localizada na região nordeste do país - a Universidade Federal da Paraíba (UFPB). Para tanto, foi analisado o Projeto Pedagógico do Curso (PPC) em vigência. 


\section{$e$-Curriculum}

Para melhor compreender esse panorama serão tratadas, sucintamente, as origens do currículo no Brasil e, em seguida, abordados alguns enfoques e contribuições das teorias curriculares. Por fim, realizou-se algumas reflexões sobre como é construído o currículo no curso do Bacharelado em Turismo que foi alvo desta investigação, considerando a política educacional para os cursos de graduação no país.

\section{CURRÍCULO UNIVERSITÁRIO NO BRASIL}

Sobre as origens do pensamento curricular no país, bem como suas concepções e princípios, constata-se que aparecem a partir das reformas educacionais da década de 1920 a 1930, período em que foi criado o Ministério da Educação e quando o Brasil se inseria no modo de produção capitalista ${ }^{1}$. Os primeiros estudos sobre currículo são baseados nas ideias escolanovistas, derivadas de conceitos progressivistas de Dewey e Kilpatrick.

Moreira (1990) sugere que as ideias progressivistas que fundamentaram o primeiro enfoque sistemático de questões curriculares eram, em geral, coerentes com as transformações econômicas, políticas e sociais depois de 1930. Essas ideias harmonizavam-se para estabelecer uma tradição educacional moderna no país e para construir uma sociedade industrial também moderna.

Nos anos 1950 a 1970, a influência norte-americana aumentou em decorrência de acordos de cooperação entre os dois países - Brasil e Estados Unidos (USA). No que se refere especificamente a currículos e programas, Moreira (1990) explica que o golpe militar de 1964 e todo o panorama político, econômico, ideológico e educacional do país conduziram as políticas para substanciais transformações. Diversos acordos foram assinados com os Estados Unidos visando à modernização e a racionalização do país. As discussões sobre currículo espalharam-se e essa demanda direcionou para a inclusão da disciplina de "Currículos e Programas" nos cursos superiores. A tendência tecnicista passou a prevalecer, em sintonia com o discurso de eficiência e modernização adotado pelos militares, e diluiu não só a ênfase às necessidades individuais da tendência progressivista, mas também as intenções emancipatórias das orientações críticas, incompatíveis com a doutrina de segurança nacional que passou a orientar as decisões governamentais. Assim, a preocupação principal passou a 


\section{$e$-Curriculum}

Programa de Pós-Graduação em Educação: Currículo

ser a eficiência do processo pedagógico, indispensável ao treinamento adequado do capital humano do país.

Consta nos documentos legais que, em 1968, foi realizada no Brasil uma reforma universitária, com a Lei 5.540, de 28 de novembro de 1968, que fixou normas de organização e funcionamento do ensino superior e sua articulação com a escola média. Essa reforma, segundo Martins (2009), produziu efeitos paradoxais no ensino superior brasileiro. Por um lado, modernizou uma parte significativa das universidades federais e determinadas instituições estaduais e confessionais, que incorporaram gradualmente as modificações acadêmicas propostas pela reforma. E por outro, possibilitou o surgimento do "novo" ensino superior privado no país.

A década de 1980, por sua vez, ficou conhecida como a década perdida, pois foi um período de crise e de altas taxas de inflação. Nesse período, cresce a influência de autores europeus e o pensamento curricular brasileiro contemporâneo é dominado pela tendência crítica. Para Moreira (1990, p. 161):

O foco passa a ser no discurso educacional europeu, mais que no americano, assim como o aumento do número de pós-graduações realizadas no Brasil e o desenvolvimento de centros nacionais de excelência parecem representar tanto uma tentativa de definir uma tradição pedagógica mais autônoma, como uma reação contra a influência americana nos anos sessenta e setenta, quando o Brasil importou modelos educacionais americanos que contribuíram para a divisão do trabalho pedagógico e o surgimento de especialistas em educação, inclusive do supervisor e curriculista.

No fim da década de 1980, o currículo no Brasil passa a ser construído e vivido em um novo cenário, principalmente em decorrência das mudanças políticas e da redemocratização no país. Nesse sentido, rompe-se a tendência tecnicista, funcionalista e, por conseguinte, surgem as tendências e teorias ligadas ao enfoque sociológico.

No início dos anos 1990, os estudos, as pesquisas e produções no campo curricular caracterizavam-se fortemente pelo enfoque sociológico - fundamentado em teóricos ligados à nova Sociologia da Educação - com a compreensão do currículo enquanto lócus privilegiado onde acontecem as relações de poder.

Menezes e Araújo (2011) contribuem nessa linha de tempo quando apontam que o século XX é marcado por profundas transformações em todos os campos e dimensões: político, social, econômico e tecnológico. E que a sociedade pós-industrial impõe novos 


\section{$e$-Curriculum}

desafios: a produção de bens simbólicos que alteram as ênfases até então existentes. $\mathrm{Na}$ tentativa de compreender essas ênfases, o pensamento curricular incorpora enfoques pósmodernos e pós-estruturais. Teóricos como Foucault, Derrida, Deleuze, Guattari e Morin influenciaram e ainda influenciam fortemente as construções teóricas nesse campo. Contudo, um novo movimento vai se consolidando. Se antes havia como marca desse campo, a linearidade e a homogeneidade de referências; a partir deste período (anos 1990), as referências ganham a característica da multiplicidade, não apenas como diferentes tendências e orientações teórico-metodológicas, mas também como tendências e orientações que se interrelacionam produzindo os multi e trans - que na segunda metade da década são a grande marca e contribuição no campo curricular no Brasil.

$\mathrm{Na}$ atualidade, o suporte teórico está amparado nos estudos pós-modernistas e pósestruturalistas. Assim, pode-se classificar essa fase como pós-crítica. Conforme Silva (2002, p. 16):

Da perspectiva pós-estruturalista, podemos dizer que o currículo é também uma questão de poder e que as teorias do currículo, na medida em que buscam dizer o que o currículo deve ser, não podem deixar de estar envolvidas em questões de poder. Selecionar é uma operação de poder. Privilegiar um tipo de conhecimento é uma questão de poder.

As questões inerentes ao currículo não podem ser dissociadas de três elementos: primeiro, a questão de poder nas IES; segundo, os atores envolvidos e as relações interpessoais (relações essas que ocorrem dentro de um campo e sofrem influências dos diversos atores e das respectivas relações de poder existentes no campo) e, por último, o contexto em que esses currículos são formados (incorporando e convivendo com as diferenças, as questões de gênero, etnia, sexualidade).

\section{CONTRIBUIÇÕES DAS TEORIAS DE CURRÍCULO}

Currículo significa caminho, trajeto, percurso, pista ou circuito atlético. Segundo Sacristán (2000), o termo vem da palavra latina currere, referindo-se à carreira, um percurso a ser atingido. Nessa conjuntura, não há consenso sobre o que é currículo. Moreira (1997) explica que isso ocorre, sobretudo, porque é um conceito relacionado a uma complexidade de problemas e a uma construção cultural, histórica e socialmente determinada. E que esses problemas dificultam um sentido único. 


\section{$e$-Curriculum}

No campo da educação especificamente, esses múltiplos conceitos conduzem para o currículo com uma pluralidade de significados - o que se pode observar quando são inúmeros os conceitos que variam segundo autores, períodos e ideologias. Segundo Gagné e Briggs (1987), currículo é "grupo de materias o áreas que constituyen un plan de estudios, es decir, una serie de unidades de contenido".

Nesse sentido, as teorias de significado na racionalidade técnica-linear, como abordado, tiveram significativa influência no Brasil. Moreira (1990) expõe que a característica básica do paradigma técnico-linear é a ênfase nos objetivos, estratégias, controle e avaliação, ou seja, a definição dos elementos e variáveis relevantes envolvidas no currículo e com a criação de um sistema de tomada de decisões para o desenvolvimento curricular. A teoria que melhor exemplificaria essa dupla preocupação seria a de Tyler, expandida e aperfeiçoada posteriormente, por Taba.

Sobre o paradigma formulado por Tyler (1976 apud Silva, 2002) esclarece-se que esse centra-se em questões de organização e desenvolvimento. $\mathrm{O}$ currículo é essencialmente uma questão técnica. A organização e o desenvolvimento do currículo na perspectiva de Tyler se estruturam em torno de quatro perguntas centrais que devem ser respondidas, para que o processo de elaboração do currículo se desenvolva: 1. Que objetivos educacionais deve a escola procurar atingir?; 2. Que experiências educacionais podem ser oferecidas que tenham a probabilidade de alcançar esses objetivos?; 3. Como organizar eficientemente essas experiências educacionais?; 4. Como podemos ter certeza de que esses objetivos estão sendo alcançados?

Essas perguntas podem ser formuladas no processo de quatro fases por meio do qual o currículo é elaborado: enunciar objetivos, selecionar experiências de aprendizagem, organizar experiências de aprendizagem e avaliar. Apesar de ser um representante da teoria tecnicista, Moreira (1990) destaca que, em relação às experiências de aprendizagem, Tyler enfatiza a importância de examinar questões sociais. $\mathrm{O}$ autor afirma ainda que os princípios progressivistas encontram-se na preocupação de Tyler com a integração das experiências curriculares e que em termos de organização curricular, não se pode associar Tyler a um interesse essencialmente técnico.

No paradigma da racionalidade técnica, Taba (1974) representa uma continuação do trabalho de Tyler, acentuando a necessidade de elaborar os programas escolares baseando-se em uma teoria curricular que se fundamenta nas exigências e necessidades da sociedade e da 


\section{$e$-Curriculum}

cultura. O modelo curricular de Taba considera a necessidade de: diagnóstico das necessidades; formulação de objetivos; seleção de conteúdos; organização dos conteúdos; seleção das experiências de aprendizagens; organização das experiências de aprendizagens; determinação dos processos de avaliação.

Moreira (1990) esclarece que existe um interesse em compreensão que subjaz a teoria de Taba e que a influência progressivista observada em Tyler também é evidente na autora. As duas teorias (Tyler e Taba) permanecem restritas ao horizonte do capitalismo liberal.

Por fim, apresentam-se as teorias crítica e pós-crítica. Na primeira, há crítica à escola como reprodutora da hegemonia dominante e das desigualdades sociais, há crítica à racionalidade técnica da escola. Essa corrente tem como seus expoentes: Apple (2006), Giroux (1992), Althusser (1998) e Saviani (1998). A segunda é fundamentada no pósestruturalismo, no multiculturalismo, com valorização da subjetividade e do currículo como elemento de construção de identidades.

Sintetizando as questões da teoria tradicional, crítica e pós-crítica, Silva aponta que cada teoria tinha uma ênfase a seguir:

As teorias tradicionais eram teorias da aceitação, ajuste e adaptação. As teorias críticas são teorias de desconfiança, questionamento e transformação radical. Para as teorias críticas o importante não é desenvolver técnicas de como fazer o currículo, mas desenvolver conceitos que nos permitam compreender o que o currículo faz (SILVA, 2002, p. 30).

Assim sendo, é importante salientar que, de acordo com Moreira (1990), os autores críticos não costumam ser muito precisos em termos de organização curricular e, conforme depoimentos de professores, existem muitas lacunas sobre recomendações práticas das teorias críticas. Enquanto que, embora os autores tecnicistas e progressivistas ofereçam uma visão fragmentada e supostamente neutra do processo pedagógico, há neles diretrizes orientadoras claras e que podem ser seguidas sem maiores dificuldades, desde que se garantam determinadas condições e recursos.

\section{A CONSTRUÇÃO DO CURRÍCULO DE BACHARELADO EM TURISMO}

Os cursos de turismo integram a área de Hospitalidade, que engloba um complexo grupo de atividades econômicas e profissionais inter-relacionadas entre si. No que diz respeito 


\section{$e$-Curriculum}

aos cursos superiores da área de hospitalidade, estes podem ser cursos de bacharelado ou superiores de tecnologia. Os cursos de bacharelado são em: Turismo; Hotelaria e Gastronomia. Já os cursos superiores de tecnologia, segundo o Catálogo Nacional de Cursos Superiores de Tecnologia, pertencem ao eixo "Hospitalidade e lazer", podendo ter as seguintes denominações: Eventos; Gastronomia; Gestão desportiva e de lazer; Gestão de Turismo e Hotelaria (MEC, 2010). Sobre as denominações e os cursos existentes na área de Hospitalidade, essa diversidade também pode ser encontrada em outros países.

No Brasil, de acordo com dados do Censo da Educação Superior - MEC/INEP (2014), existem 516 cursos ativos na área de Hospitalidade, sendo que a maioria é de Bacharelado em Turismo (222 cursos). Em seguida, relativamente à quantidade de cursos oferecidos, a oferta nacional está distribuída da seguinte forma: Tecnólogo em Gastronomia (121); Tecnólogo em Gestão de Turismo (61); Tecnólogo em Hotelaria (36); Tecnólogo em Eventos (42); Bacharelado em Hotelaria (23); Bacharelado em Gastronomia (9) e Tecnólogo em Planejamento e Organização do Turismo (2).

Ao comparar esses dados com o Censo da Educação Superior - MEC/INEP (2011), evidencia-se que houve uma diminuição tanto do número dos cursos de Bacharelado em Turismo quanto dos cursos da área, pois em 2011 eram 285 cursos de Bacharelado em Turismo e, em 2014, 222 cursos. Já os cursos da área passaram de 566, em 2011, para 516 em 2014 - o que significa uma redução de $7 \%$ dos cursos de turismo e de $8,9 \%$ em cursos da área. Esses dados comprovam uma mudança no que diz respeito à formação na área de Hospitalidade, especialmente nos cursos de turismo.

Sobretudo, os dados cristalizam que, ao longo dos anos, os cursos passaram por inúmeras modificações. No início, a predominância era de cursos de Bacharelado em Turismo e, atualmente, são oferecidos cursos de bacharelado (com títulos em Turismo, Hotelaria e Gastronomia) e tecnólogos (com títulos em Gestão de Turismo, Hotelaria, Gastronomia, Eventos e Planejamento e organização do turismo).

Esse panorama aponta o crescimento dos demais cursos da área de Hospitalidade, especialmente dos tecnólogos. Tal fato pode estar relacionado com a formação profissional. Os cursos superiores de tecnologia têm a formação focada no mercado e com grande especialidade na área de formação; enquanto os de bacharelado conferem uma formação mais abrangente e preparam o aluno para atuar em diversas áreas dentro de uma determinada 


\section{$e$-Curriculum}

profissão e, também, com uma formação científica. O profissional de turismo tem uma formação mais generalista.

Nesse sentido, é importante analisar como ocorre a construção do currículo do curso de Bacharelado em Turismo considerando a influência da política educacional para os cursos de graduação no país, uma vez que este currículo reflete na formação recebida pelo egresso.

De acordo com a LDB, Art. 53, inciso II, as IES devem fixar os currículos dos seus cursos e programas, observadas as diretrizes gerais pertinentes. Em 1997, dando seguimento à política educacional, o Conselho Nacional de Educação (CNE) aprova o Parecer CNE/CES Nº 776/97, que trata da orientação para as Diretrizes Curriculares dos Cursos de Graduação $(\mathrm{DCN})$.

No Brasil, as IES têm por tarefa elaborar o PPC em consonância com os propósitos da instituição. E nesse sentido, há necessidade de estar em sintonia com o Plano de Desenvolvimento Institucional (PDI). Portanto, cada curso dispõe de seu projeto pedagógico tendo em vista as especificidades da respectiva área de atuação. O PPC de graduação expressa os principais parâmetros para a ação educativa.

De acordo com Ministério da Educação - MEC (2006), o currículo é um importante elemento da organização acadêmica. É concebido como um espaço de formação plural, dinâmico e multicultural, fundamentado nos referenciais socioantropológicos, psicológicos, epistemológicos e pedagógicos em consonância com o perfil do egresso previsto nas Diretrizes Curriculares. Esses referenciais instituem o currículo como um conjunto de elementos que integram os processos de ensinar e de aprender num determinado tempo e contexto, garantindo a identidade do curso e o respeito à diversidade. Assim, o currículo é um dos elementos constitutivos do PPC, tendo como orientação básica as Diretrizes Curriculares Nacionais.

Nesse documento constam: os conhecimentos e saberes considerados necessários à formação das competências estabelecidas a partir do perfil do egresso; estrutura e conteúdo curricular; ementário; bibliografias básica e complementar; estratégias de ensino; docentes; recursos materiais; serviços administrativos; serviços de laboratórios; e infraestrutura de apoio ao pleno funcionamento do curso.

A análise documental do PPC do curso em análise neste estudo permite inferir que a educação superior em turismo está aliada as políticas públicas educacionais do país. O PPC 


\section{$e$-Curriculum}

analisado remete que, para sua formulação, foram considerados o Parecer CNE-CES 288/2003, as DCN do curso de turismo (2006) e a LDB (1996).

Desse modo, a formação do currículo nos cursos universitários no Brasil tem parâmetros bem estabelecidos de orientação determinados pelo Ministério da Educação.

A Resolução CNE/CES Nº13/2006 do MEC institui as Diretrizes Curriculares Nacionais para o curso de Bacharelado em Turismo. O Art. $2^{\circ}, \S 1^{\circ}$ estabelece que o projeto pedagógico do curso, além da clara concepção do curso de graduação em Turismo, com suas peculiaridades, apresente seu currículo pleno e sua operacionalização. No Art. $5^{\circ}$, o documento aponta que: os cursos de graduação em turismo deverão contemplar, em seu Projeto Pedagógico e em sua organização curricular, os seguintes campos interligados de formação: Conteúdos Básicos (estudos relacionados com os aspectos sociológicos, antropológicos, históricos, filosóficos, geográficos, culturais e artísticos, que conformam as sociedades e suas diferentes culturas); Conteúdos Específicos (estudos relacionados com a Teoria Geral do Turismo, Teoria da Informação e da Comunicação, estabelecendo ainda as relações do turismo com a administração, o direito, a economia, a estatística e a contabilidade, além do domínio de, pelo menos, uma língua estrangeira); Conteúdos Teórico-Práticos (estudos localizados nos respectivos espaços de fluxo turístico, compreendendo visitas técnicas, inventário turístico, laboratórios de aprendizagem e de estágios).

O PPC analisado propõe que o profissional deve compreender o turismo; para tanto "o Curso oferece ao aluno uma fundamentação teórica sólida que tem por objetivo compreender o lugar do Turismo" (UNIVERSIDADE FEDERAL DA PARAÍBA, 2010, p. 7). E corrobora que "o curso de graduação, no âmbito geral, deve contemplar a formação teórica baseada na interdisciplinaridade de diversas correntes do pensamento turístico como objeto de profundas reflexões sobre o fenômeno" (UNIVERSIDADE FEDERAL DA PARAÍBA, 2010, p. 8) e, por fim justifica que envolve no PPC a composição de diversas disciplinas de variadas áreas do conhecimento, utilizando enormemente o caráter multi e interdisciplinar do estudo do turismo e dessa forma o curso de turismo da UFPB utiliza o trabalho docente e a produção acadêmica de outros cursos da instituição (UNIVERSIDADE FEDERAL DA PARAÍBA, 2010).

O objetivo do curso, de acordo com o PPC, é desenvolver o entendimento da complexa e sistemática atividade do turismo e da hospitalidade, fomentando o empreendedorismo, investindo na capacitação e na habilitação de profissionais para o 


\section{$e$-Curriculum}

exercício de gestão de empresas turísticas, por meio do conhecimento em hospitalidade, planejamento, organização e marketing, dotando-lhe ainda de responsabilidade socioambiental e formação crítica cidadã em defesa do turismo não predatório, baseado nos princípios da sustentabilidade e do desenvolvimento socioeconômico das localidades receptoras.

O perfil do egresso expressa que deve promover uma formação interdisciplinar preparado para atuar no planejamento, administração, marketing e divulgação da atividade turística, compreendida como uma alternativa para o desenvolvimento regional, considerando-se não apenas o nível microeconômico (em termos de atuação junto às empresas), mas também o macroeconômico e social, que comporta o conhecimento e o planejamento de políticas públicas para a área.

O PPC cristaliza na proposta de formação a consciência crítica e o treinamento de técnicas, além da formação multi e interdisciplinar:

[...] deve receber uma formação interdisciplinar que o prepare para ser um técnico com formação superior, em nível de graduação, apto a planejar e executar projetos turísticos da iniciativa pública e privada, organizar e administrar empresas e instituições do setor turístico em geral, e equipamentos de turismo particulares ou públicos (UNIVERSIDADE FEDERAL DA PARAÍBA, 2010, p. 13).

Constatou-se também a formação generalista instituída no Parecer CNE-CES 288/2003, que estabelece o delineamento de um perfil profissional almejado para os egressos desses cursos:

A habilidade principal do graduado é, genericamente, entender a totalidade dos processos do turismo, suas interfaces, suas variáveis macro e microambientais e neles intervir criativamente [...] (UNIVERSIDADE FEDERAL DA PARAÍBA, 2010, p. 15).

$\mathrm{Na}$ análise da estrutura, bem como dos critérios para elaboração do currículo, constatase que existe em sua concepção influência da teoria pós-crítica e da teoria tecnicista, especialmente a de Taba (1962 apud RIBEIRO, 1992, p. 1):

Um modelo de organização curricular representa um modo de identificar os elementos curriculares básicos e de estabelecer as relações que entre eles se afirmam, indicando os princípios e formas que estruturam tais elementos num todo curricular e postulando condições de realização prática. 


\section{$e$-Curriculum}

Assim, ressalta-se a importância nesses currículos dos objetivos, da seleção e organização curricular e do sistema de avaliação. Nesse sentido, registra-se que o SINAES criado pela Lei $\mathrm{n}^{\circ} 10.861$, de 14 de abril de 2004, é formado por três componentes principais: a avaliação das instituições, dos cursos e do desempenho dos estudantes. No que concerne à avaliação dos cursos, o Instrumento de Avaliação de Cursos de Graduação (BRASIL, 2012), na dimensão organização didático-pedagógica avalia: os objetivos do curso; a estrutura e os conteúdos curriculares; a metodologia; os procedimentos de avaliação de ensinoaprendizagem e ações de avaliação do curso. Nesse sentido, os mecanismos de elaboração curricular são previstos e, para tanto, existem as DCN.

A estrutura curricular deve ser construída a partir da base mínima, indispensável para a formação profissional, pois é na organização curricular do curso que ficarão estabelecidas as condições para a efetiva conclusão e integralização curricular. A organização curricular dos cursos, chamada de estrutura superficial do currículo, ou seja, a matriz curricular, é baseada no modelo de currículo por disciplinas. Para exemplificar, seguem os Quadros 1 e 2, que demonstram resumidamente a estrutura de um curso de Bacharelado em Turismo:

\begin{tabular}{|l|c|c|c|}
\hline \multicolumn{1}{|c|}{ Conteúdos Básicos Profissionais } & Créditos & Carga Horária & Pré-requisitos \\
\hline \multicolumn{1}{|c|}{ Discinas } & 04 & 60 & Nenhum \\
\hline Sociologia do Turismo & 04 & 60 & Nenhum \\
\hline Geografia e Turismo & 04 & 60 & Introdução ao Estudo do Turismo \\
\hline Turismo, Antropologia e Cultura & 04 & 60 & Nenhum \\
\hline Teoria e Técnica do Turismo (TTT) & 04 & 60 & Nenhum \\
\hline Redação e Expressão Oral & 04 & 60 & Nenhum \\
\hline $\begin{array}{l}\text { Contabilidade de Hotelaria e } \\
\text { Restaurantes }\end{array}$ & 04 & 60 & Nenhum \\
\hline Língua Inglesa aplicada ao Turismo ou & 04 & 60 & Estágio Supervisionado I \\
\hline Língua Espanhola aplicada ao Turismo & & & \\
\hline $\begin{array}{l}\text { 1.2 Estágio Curricular } \\
\text { Supervisionado }\end{array}$ & 10 & 150 & \\
\hline Estágio Supervisionado em Turismo I & 10 & 150 & \\
\hline Estágio Supervisionado em Turismo II & & & \\
\hline
\end{tabular}

Quadro 1 - Conteúdos Básicos Profissionais

Fonte: Universidade Federal da Paraíba (2010), adaptado pela autora.

\begin{tabular}{|l|c|c|c|}
\hline Conteúdos Obrigatórios & Créditos & Carga Horária & Pré-requisitos \\
\hline Trabalho de Conclusão de Curso - TCC & 04 & 60 & $\begin{array}{c}\text { Todas obrigatórias menos } \\
\text { Estudos Turísticos Brasileiros }\end{array}$ \\
\hline Gestão de Meios de Hospedagem & 04 & 60 & $\begin{array}{c}\text { Introdução ao Estudo do } \\
\text { Turismo e Introdução à } \\
\text { Administração }\end{array}$ \\
\hline $\begin{array}{l}\text { Gestão de Alimentação e Bebidas em } \\
\text { Hospitalidade }\end{array}$ & 04 & 60 & $\begin{array}{c}\text { TTT e Introdução à } \\
\text { Administração }\end{array}$ \\
\hline
\end{tabular}




\section{$e$-Curriculum}

Programa de Pós-Graduação em Educação: Currículo

\begin{tabular}{|l|l|l|l|}
\hline Sistemas de Transporte e Turismo & 04 & 60 & TTT \\
\hline Agências e Operadoras de Turismo & 04 & 60 & TTT \\
\hline Planejamento e Organização de Eventos & 04 & 60 & Nenhum \\
\hline Metodologia do Trabalho Científico & 04 & 60 & Nenhum \\
\hline
\end{tabular}

Quadro 2 - Conteúdos Complementares/Específicos

Fonte: Universidade Federal da Paraíba (2010), adaptado pela autora.

Tendo por base os Quadros 1 e 2, recorre-se a Ribeiro (1992) para corroborar a análise, ao afirmar que tais modelos de, bem como os elementos fundamentais do currículo, sofrem um tratamento típico ao serem organizados de maneira disciplinar. As principais vantagens do modelo de organização disciplinar resultam das características (objetivos, conteúdos, estratégias de ensino e experiências de aprendizagem, avaliação e fatores de execução curricular), situando-se o relativo sucesso dessa forma tradicional de estruturação curricular - a sua permanência inquestionável no tempo - no pressuposto subjacente de que as disciplinas constituem um processo sistemático e eficiente de transmitir a herança cultural bem como de desenvolver processos e aptidões intelectuais, no modelo tradicional de formação de professores (que também segue essa estrutura curricular) e na conveniência ou facilidade de organização escolar que claramente o favorece. Dentre as limitações desse tipo de currículo está o fato de que este pode contribuir para a fragmentação de conhecimentos propostos, a falta de integração do conhecimento.

Gallo (2007) vai além da vertente disciplinar ao questionar os moldes pelos quais o conhecimento, a divisão dos saberes em áreas, em aspectos distintos que devem ser estudados, aprendidos e articulados estão organizados. Para o autor, a compartimentalização das disciplinas na composição dos currículos, de especialização dos saberes, leva as disciplinas a converterem-se em gavetas de um arquivo, compartimentos estanques, sem comunicação entre si.

Nessa premissa, a matriz curricular do curso de Bacharelado em Turismo, ao instituir pré-requisitos para determinadas disciplinas, contribui para a fragmentação do conhecimento, tendo em vista que é indispensável o processo classificatório traduzido em processos de avaliação. Nesse sentido, o processo avaliativo se apresenta dentro do paradigma positivista, e por essa perspectiva Esteban (2008) reafirma que a proposição quantitativa da avaliação é enfatizada nos resultados alcançados e na possibilidade de sua quantificação - o que prevê a uniformização dos sujeitos numa organização curricular que prioriza um conhecimento 


\section{$e$-Curriculum}

Programa de Pós-Graduação em Educação: Currículo

objetivo e factual, mantendo e estimulando as fronteiras disciplinares com uma atuação fortemente disciplinadora. Essa modalidade de avaliação está em perfeita sintonia com as proposições do paradigma dominante.

Apesar de evidenciar a racionalidade técnica no desenho curricular desses cursos, constata-se que também são contemplados na concepção desses currículos contribuições que dizem respeito às competências e a teoria pós-crítica.

No que se refere às competências, a legislação propõe que os cursos superiores sejam orientados para competências e habilidades. Nesse sentido, as DCN (CNE/CES N 776/97) ressaltam que deve-se encorajar o reconhecimento de competências desenvolvidas fora do ambiente escolar, inclusive as que se referirem à experiência profissional julgada relevante para a área de formação considerada. As DCN para o curso de Bacharelado em Turismo (2006) estabelecem, no Art. $2^{\text {o: }}$ "a organização do curso de que trata esta Resolução se expressa através do seu Projeto Pedagógico, abrangendo o perfil do formando, as competências e habilidades". O Art. $4^{\circ}$ complementa descrevendo quais competências e habilidades tal formação profissional deverá possibilitar.

Seguindo essas diretrizes da política nacional de educação, os PPC dos cursos têm definido o perfil do egresso embasado em competências e habilidades. E o Instrumento de Avaliação de Cursos de Graduação (BRASIL, 2012), na dimensão organização didáticopedagógica, avalia também o perfil do profissional egresso, além dos aspectos já citados anteriormente.

Os conteúdos devem ser integrados para atingir essas competências. A educação moderna deve formar pessoas preparadas para o contexto da realidade social e do trabalho, ou seja, o saber fazer que significa o valor de uso expresso por Costa (2005) com habilidades e competências necessárias para o exercício do trabalho.

A profissionalização, assim, se dá por uma racionalidade em torno da ideia da formação do sujeito para resolver situações do cotidiano que envolvem diferentes graus de complexidade. Entretanto, a sociedade precisa de um sujeito integral, com perfil crítico e, nesse aspecto, o currículo por disciplinas parece não ser suficiente.

Nesse sentido, Gallo (2007) afirma que o currículo disciplinar, imageticamente representado na e pela árvore, faz de nós seres fragmentados, mas fragmentados que remetem a uma unidade perdida. E propõe que devemos pensar o currículo na perspectiva rizomática e não como árvore. As disciplinas não seriam galhos que não se comunicam, mas tenderiam a 


\section{$e$-Curriculum}

soar como galhos que se conectam e que se misturam, teias de possibilidades, multiplicidades de nós, de conexões, de interconexões.

Já no que diz respeito à perspectiva da teoria pós-crítica, a construção do currículo universitário em cursos de Bacharelado em Turismo parece sofrer influência da teoria póscrítica na concepção dos currículos, ao trazer as relações sociais e sua discussão para a sala de aula: questões de raça, gênero, cultura, identidade e subjetividade, a compreensão do para quem se constrói o currículo.

A estrutura dos cursos no currículo prescrito está embasada nas teorias tecnicistas, por sua vez os objetivos dos cursos e o perfil dos egressos apontam para uma formação crítica. Ao debater a questão da formação recebida, os egressos identificaram que recebem uma formação, crítica, humanista, de pensar, refletir, encaixando-se nos princípios da racionalidade crítica.

Portanto, essas questões estão articuladas com o que apregoa a Resolução CNE/CP N 01 de 17/06/2004, que institui as Diretrizes Curriculares Nacionais para Educação das Relações Etnicorraciais e para o Ensino de História e Cultura Afrobrasileira e Africana. As diretrizes defendem que essas orientações de conteúdos a serem incluídos e trabalhados, em todos os níveis e modalidades de ensino, conforme estabelece a resolução no Art. $1^{\circ}, \S 1^{\circ}$, sejam incluídas nos conteúdos de disciplinas e atividades curriculares dos cursos que ministram a Educação das Relações Étnico-Raciais, bem como o tratamento de questões e temáticas que dizem respeito aos afrodescendentes, nos termos explicitados no Parecer $\mathrm{CNE} / \mathrm{CP} / \mathrm{N}^{\circ} 3 / 2004$ e, complementam no $\S 2^{\circ}$, que o cumprimento das referidas diretrizes curriculares, por parte das instituições de ensino, será considerado na avaliação das condições de funcionamento do estabelecimento.

De acordo com o Parecer, esses dispositivos legais, bem como reivindicações e propostas do Movimento Negro ao longo do século XX, apontam para a necessidade de diretrizes que orientem a formulação de projetos empenhados na valorização da história e cultura dos afro-brasileiros e dos africanos, assim como comprometidos com a educação de relações étnico-raciais positivas. Ou seja, o Parecer procura oferecer uma resposta, entre outras, na área da educação, à demanda da população afrodescendente, no sentido de políticas de ações afirmativas, isto é, de políticas de reparações e de reconhecimento e valorização de sua história, cultura, identidade. 


\section{$e$-Curriculum}

As teorias pós-críticas têm ênfase no multiculturalismo, na identidade/subjetividade, nas questões culturais, de gênero, étnicas e raciais. Essas prerrogativas legais quanto às questões multiculturais e de identidade são efetivamente atendidas nas práticas de cursos de turismo em virtude de sua filosofia, uma vez que esse profissional, no cotidiano do seu trabalho, deve "bem receber" os turistas de diferentes origens. Nesse sentido, deve privilegiar os aspectos sociais e ambientais, promovendo o intercâmbio entre os povos, o respeito à diversidade cultural e étnica, ou seja, as diferenças de sexo, raças, comportamentos, culturas, credos, entre outras.

\section{CONSIDERAÇÕES FINAIS}

Este estudo de caso analisou a formação do currículo universitário em um curso de Bacharelado em Turismo considerando a política educacional para os cursos de graduação no país.

Os currículos não podem ser concebidos como um projeto estático, mas como uma realidade em permanente construção. Eles são constituídos em um contexto socieconômico, político, cultural e ideológico. Construídos e vividos pelos agentes envolvidos nos processos de ensino e aprendizagem, ou seja, no processo educativo de uma determinada instituição.

Nessa premissa, a política educacional nacional no Brasil, a partir de meados dos anos 1990 passa por um processo de reestruturação. Catani, Oliveira e Dourado (2001) afirmam que o contexto da política de reforma curricular dos cursos de graduação no Brasil está associado a alterações que são decorrentes do mundo do trabalho e provocadas pela reestruturação produtiva, interferindo diretamente na esfera da produção do conhecimento e da formação profissional. De tal modo que essa política objetiva e orienta também a flexibilização da formação nos cursos de graduação para uma adaptação permanente a cada nova realidade do mercado. E é também com uma legislação específica que se definem os parâmetros educacionais, que as instituições de ensino superior devem seguir para elaborar os Projetos Pedagógicos de Curso. No que se refere à educação superior, podemos destacar as orientações advindas da legislação em documentos como a Lei de Diretrizes e Bases; nas Diretrizes Curriculares Nacionais e no Sistema Nacional de Avaliação de Cursos Superiores, que norteiam a construção dos currículos. 


\section{$e$-Curriculum}

Encontra-se no currículo proposto a adoção de uma racionalidade técnica que reflete na formação do profissional e podem estar ligada às exigências de mercado. Essa racionalidade corresponde à organização curricular na seleção dos objetivos, conteúdos, metodologias e na avaliação. Tal fato é observado por autores da área que, entre outras questões, levantam que a organização curricular do ensino superior brasileiro é voltada para a transmissão de conhecimentos e experiências aos discentes (MASETTO, 1998; VASCONCELOS, 2000).

Entretanto, a análise da construção do currículo universitário do curso de Bacharelado em Turismo que foi objeto deste artigo possibilitou também detectar a influência da teoria pós-crítica na concepção dos currículos ao trazer as relações sociais e sua discussão para a sala de aula: questões de raça, gênero, cultura, identidade e subjetividade, a compreensão do para quem se constrói o currículo.

É importante registrar que as questões de multiculturalismo e identidade são prerrogativas legais para os cursos de graduação em todas as áreas de conhecimento no Brasil. No caso dos cursos de turismo, tais prerrogativas são bem implementadas em decorrência das características e filosofia do curso, o que pode muitas vezes não ocorrer na prática em cursos de outras áreas, ou seja, não conseguir implementar os principais teóricos da teoria póscrítica, e nesse sentido, caracterizar uma ausência de legitimação dessa teoria.

Sobretudo, observou-se também que há a definição do perfil profissional, com competências e habilidades desejáveis para o egresso que deve permitir o atendimento a uma racionalidade do mercado.

Contudo, é importante a realização de estudos considerando a relação entre currículo, formação profissional e mercado de trabalho, uma vez que se constata o fechamento de cursos de Bacharelado em Turismo no país.

Por fim, conclui-se que apesar da proposta da política educacional orientar para uma maior flexibilização dos currículos de graduação ao eliminar o currículo mínimo, evidencia-se que há um modelo a ser seguido nos delineamentos estabelecidos pela política nacional de educação e que por meio do Sistema Nacional de Avaliação de Cursos tem-se um mecanismo de regulação e controle dos padrões para os cursos de graduação. 


\section{REFERÊNCIAS}

ALTHUSSER, L. Aparelhos ideológicos de Estado: nota sobre os aparelhos ideológicos de Estado. $7^{\text {a }}$ Ed. Rio de Janeiro: Graal, 1998.

APPLE, M. Ideologia e currículo. 3a Ed. Porto Alegre: Artmed, 2006.

BARRETTO, M.; TAMANINI, E.; SILVA, M. I. P. da. Discutindo o ensino universitário de turismo. Campinas: Papirus, 2004.

BRASIL, Conselho Nacional de Educação. Resolução CNE/CP N 1, de 17 de junho de 2004. Disponível em: <

http://portal.mec.gov.br/index.php?option=com_content\&id=12992:diretrizes-para-aeducacao-basica > Acesso em: 09/05/2014.

. Parecer CNE/CP n. ${ }^{\circ}$ 3, de 10 de março de 2004. Disponível em: < http://portal.mec.gov.br/index.php?option=com_content\&id=12992:diretrizes-para-aeducacao-basica > Acesso em: 09/05/2014.

Ministério da Educação. Resolução CNE/CES Nº13, de 24 de novembro de 2006 Diretrizes Curriculares Nacionais do Curso de Graduação em Turismo. Brasília: Câmara de Educação Superior. Disponível em: < http://portal.mec.gov.br/cne/arquivos/pdf/rces13_06.pdf. > Acesso em: 06/05/2014.

MEC/Instituto Nacional de Estudos e Pesquisas Educacionais Anísio Teixeira INEP. Censo da Educação Superior 2005. Disponível em: < http://portal.inep.gov.br/superior-censosuperior-sinopse > Acesso em: 07/05/2015.

Censo da Educação Superior 2011. Disponível em: < http://portal.inep.gov.br/superior-censosuperior-sinopse > Acesso em: 15/05/2015.

Censo da Educação Superior 2014. Disponível em: < http://portal.inep.gov.br/superior-censosuperior-sinopse > Acesso em: 14/05/2016.

. Parecer CNE/CES N776, de 03 de dezembro de 1997 - Orientação para as diretrizes curriculares dos cursos de graduação. Disponível em: < http://portal.mec.gov.br/cne/arquivos/pdf/CES0776.pdf. > Acesso em: 09/05/2014.

Parecer CNE/ CES 288/2003. Disponível em: < http://portal.mec.gov.br/index.php?option=com_content\&view=article\&id=13241:parecerces-2003\&catid=323: orgaos-vinculados > Acesso em: 26/05/2014.

Instrumento de avaliação de cursos de graduação. - Brasília: Instituto Nacional de Estudos e Pesquisas Educacionais Anísio Teixeira, 2006. Disponível em: < http://www.uesb.br/cpa/downloads/leituras/INSTRUMENTO\%20DE\%20AVALIA\%C3\%87 


\section{$e$-Curriculum}

\%C3\%830\%20DE\%20CURSOS\%20DE\%20GRADUA\%C3\%87\%C3\%82O.pdf. > Acesso em: 06/05/2014.

. Instrumento de Avaliação de Cursos de Graduação Presencial e a Distância.

Brasília: Instituto Nacional de Estudos e Pesquisas Educacionais Anísio Teixeira, 2012.

Disponível em: <

http://download.inep.gov.br/educacao_superior/avaliacao_cursos_graduacao/instrumentos/20 12/instrumento_com_alteracoes_maio_12.pdf. > Acesso em: 06/05/2014.

Presidência da República. Lei N9. 394 de 20 de dezembro de 1996 - Diretrizes e Bases da Educação Nacional - LDB. Disponível em: < http://portal.mec.gov.br/arquivos/pdf/ldb.pdf. > Acesso em: 06/05/2014.

Lei N¹0. 861 de 14 de abril de 2004 - Sistema Nacional de Avaliação da educação Superior (SINAES). Brasília: Casa civil. Disponível em: < http://www.planalto.gov.br/ccivil_03/_ato2004-2006/2004/lei/110.861.htm > Acesso em: 07/05/2014.

Lei No11. 645 de 10 de março de 2008. Disponível em: < http://www.planalto.gov.br/ccivil_03/_ato2007-2010/2008/lei/111645.htm. Acesso em: 09/05/2014.

CATANI, Afrânio Mendes; OLIVEIRA, João Ferreira; DOURADO, Luiz Fernandes. Política educacional, mudanças no mundo do trabalho e reforma curricular dos cursos de graduação no Brasil. Educação e Sociedade, v. 22, n. 75, p. 67-83, 2001.

COSTA, T. A. A noção de competência enquanto princípio de organização curricular. Revista Brasileira de Educação, 2005. Disponível em: < http://www.redalyc.org/pdf/275/27502905.pdf > Acesso em: 06/05/2014.

ESTEBAN, M. T. Ser professora: avaliar e ser avaliada. In: ESTEBAN, M. T. Escola, currículo e avaliação. São Paulo: Cortez, 2008.

GAGNÉ, R. M. e BRIGGS, L. La planificación em enseñanza: sus princípios. México: Trillas, 1987.

GALLO, S. Currículo (entre) imagens e saberes. Palestra proferida no V Congresso Internacional de Educação. São Leopoldo: UNISINOS, 2007. Disponível em: < http://www.grupodec.net.br/ebooks/GalloEntreImagenseSaberes.pdf. > Acesso em: 22/05/2014.

GIROUX, H. A escola crítica e a política cultural. $3^{\text {a }}$ ed. São Paulo, Cortez, 1992.

SACRISTÁN J. Gimeno. O currículo: os conteúdos do ensino ou uma análise prática. In: PÉREZ GÓMEZ, A. I. Compreender e transformar o ensino. 4. ed. Porto Alegre: ArtMed, 2000. Cap. 6, p. 119-148. 


\section{$e$-Curriculum}

MARTINS, C. B. A reforma universitária de 1968 e a abertura para o ensino superior privado no Brasil. In: Educ. Soc., Campinas, vol. 30, n. 106, p. 15-35, jan./abr. 2009. Disponível em: $<$ http://www.cedes.unicamp.br > Acesso em: 02/05/2014.

MASETTO, M. T. Docência na universidade. Campinas: Papirus, 1998.

MENEZES, A. C. S.; ARAUJO, L.M. Currículo, Contextualização e Complexidade: espaço de interlocução de diferentes saberes. Caderno Multidisciplinar-Educação e contexto do Semi-árido Brasileiro: Currículo contextualização e complexidade: Elementos para pensar a escola no Semi-árido, v. 1, 2011. Disponível em: <

http://www.irpaa.org/publicacoes/artigos/artigo-lucin-ana-celia.pdf > Acesso em: 02/05/2014.

MOREIRA, A.F.B. Currículos e programas no Brasil. Campinas: Papirus, 1990.

(Org.). Currículo: questões atuais. Campina: Papirus, 1997.

RIBEIRO, A. C. (1992). Modelos de organização curricular. In: Teoria e Desenvolvimento Curricular (8. ${ }^{a}$ Ed.). Lisboa: Texto Editora. Disponível em: <

http://www3.uma.pt/liliana/index.php?option=com_docman\&task=doc_download\&gid=514\& Itemid=26. $>$ Acesso em 08/05/2014.

RODRIGUES, D. M. L. e MENEZES, P. D. L. de. Formação docente em turismo: uma aproximação teórica. In: VII Seminário da Associação Brasileira de Pesquisa e PósGraduação em Turismo (2010). Universidade Anhembi Morumbi - UAM/ São Paulo/SP. Disponível em: < http://www.eventos.univerciencia.org/turismo/index.php/seminANPTUR/2010/paper/downlo adSuppFile/699/262 > Acesso em: 18/04/2014.

SILVA, T. T. da. Documentos de identidade: uma introdução às teorias do currículo. 2. ed. Belo Horizonte: Autêntica, 2002.

TABA, H. Elaboración del curriculo: teoría y práctica. Buenos Aires: Troquel, 1974.

UNIVERSIDADE FEDERAL DA PARAÍBA. Projeto pedagógico do curso de bacharelado em turismo 2010. [Impresso]. João Pessoa: Universidade Federal da Paraíba, 2010 .

VASCONCELOS, M. L. M. C. A formação do professor do ensino superior. 2. ed. São Paulo: Pioneira, 2000.

Artigo recebido em 21/01/2015. Aceito para publicação em 04/12/2016.

\footnotetext{
${ }^{1}$ É importante registrar que nesse período $75 \%$ da população brasileira era analfabeta e a formação de muitos era mecanicista, ou seja, voltada à execução de um trabalho.
} 